\title{
DIÁLOGOS SOBRE EDUCAÇÃO PROFISSIONAL NO CAMPUS CAICÓ: CRIANDO RAÍZES PARA VOLTAR E EXPONDO MOTIVOS PARA FICAR
}

\author{
Cynara Tércia Martins Borges ${ }^{1}$ \\ Débora Suzane de Araújo Faria ${ }^{1}$ \\ Elvis Rossini Brito de Medeiros Soares ${ }^{1}$ \\ Joaildo Maia ${ }^{2}$ \\ Márcia Maria Avelino Dantas ${ }^{1}$
}

\section{RESUMO}

A educação profissional que é ofertada pelos Institutos Federais precisa ser divulgada junto à sociedade. Para tanto, faz-se necessário socializar aos estudantes os cursos ofertados, além da possibilidade de trabalho, elevação da escolaridade e reconhecimento social. Os Institutos Federais oportunizam a profissionalização em áreas específicas, o desenvolvimento de projetos locais, a inclusão social, o incentivo à formação humana, o reconhecimento da produção de trabalhos que envolvem ensino, pesquisa e extensão. Buscando socializar esses aspectos junto à comunidade Seridoense, o Projeto de Extensão intitulado Diálogos sobre Educação Profissional objetiva realizar encontros quinzenais no Campus Caicó numa forma de socializar e divulgar os nossos cursos, oportunizando a realização de oficinas pedagógicas com estudantes de escolas públicas de Caicó que estão cursando o 9응 ano do ensino fundamental ou concluíram o ensino médio. Essa ação possibilita o acesso dos jovens a um ensino de qualidade.

Palavras-chave: diálogos; visitantes; estudantes.

\section{INTRODUÇÃO}

A educação profissional torna-se uma necessidade vital para o indivíduo, uma vez que possibilita o desenvolvimento individual e social deste e o prepara para as exigências das profissões do futuro. A educação profissional então, embasada nessas exigências, deverá fornecer um crescimento contínuo.

No entanto, a realidade nos mostra que, na medida em que diminuímos a desigualdade social entre os que estão dentro de uma escola de melhor qualidade, os Institutos Federais, nos deparamos com as desigualdades entre uma

1 Técnicos-administrativos do Campus Caicó.

2 Professor de matemática do campus Caicó. 
imensa maioria que sai de outras escolas com uma formação que, do ponto de vista cognitivo, está distante das necessidades que a revolução tecnológica exige.

Embasados nessa realidade, as ações do Projeto de Extensão Diálogos sobre Educação Profissional: Papo cabeça sobre os cursos ofertados pelo IFRN Campus Caicó prioriza oportunizar a todos maior acesso a uma escola de qualidade.

Buscando melhorar o acesso à educação profissional de qualidade, convidamos os estudantes de 10 (dez) escolas, entre Municipais e Estaduais com ensino fundamental anos finais e ensino médio para visitar o IFRN - Campus Caicó, com o intuito de divulgar os cursos, como também as ações de pesquisa e extensão.

De acordo com as metas do projeto de extensão, mensalmente, iniciando em agosto e terminando em dezembro de 2013, os estudantes das referidas escolas visitaram o Campus. O Instituto disponibilizava o transporte para ida e vinda dos estudantes, que ao chegar recebiam um adesivo com os dizeres "Sou + Visitante do IFRN", sendo direcionados para o Auditório, onde ouviam uma explanação sobre os cursos e processos seletivos em vigor. Na sequência eram direcionados para fazer um percurso, objetivando conhecer a infraestrutura do Campus. Após a visita lanchavam no refeitório, sempre acompanhados pelos bolsistas e pela equipe do projeto. Para finalizar, visitavam o parque poliesportivo.

O presente artigo está estruturado em 02 partes, a primeira parte ilustra, por meio de fotografias, a visita da primeira escola, Escola Municipal Professor Mateus Viana, que inaugurou o Projeto de Extensão e na segunda parte será feita a conclusão.

\section{SOU + VISITANTE DO IFRN - CAMPUS CAICÓ}

Em 2008 o Centro Federal de Educação Tecnológica do Rio Grande do Norte (CEFET) transformou-se em Instituto Federal de Educação, Ciência e Tecnologia do Rio Grande do Norte (IFRN), e, através do Projeto de expansão da Rede Federal, que em sua fase II, caracterizouse pela interiorização da Educação Profissional e Tecnológica no RN, foram implantadas mais seis Unidades de Ensino, que passaram a se chamar Campus. Dentro dessa interiorização a Cidade de Caicó foi contemplada com a vinda de um Campus, que entrou em exercício administrativo a partir de 23 de março de 2009. A proposta sistêmica era que os campi do Interior passassem a ofertar cursos que se relacionassem com a organização econômica da Região e, embasado nesse princípio, o Campus Caicó oferta os cursos de Informática, Eletrotécnica, Vestuário, Têxtil, a Licenciatura em Física, além dos cursos do Programa Pronatec e Mulheres Mil.

As propostas dos cursos foram compiladas em um folder e também esquematizadas em slides, que eram exibidos para os estudantes que visitaram o Campus Caicó. Na ocasião da visita, o espaço escolar foi elucidado enquanto instrumento de educação, propondo a análise desse espaço como construção cultural, já que expressa e reflete os discursos para além de sua materialidade. Assim, fundamentados em Viñao (2005) refletiremos sobre esta particularidade do entendimento da cultura escolar inserida no curso técnico e, de acordo com seu ponto de vista, cita que:

[...] a instituição escolar ocupa um espaço que se torna, por isso, lugar. Um lugar específico, com características determinadas, aonde se vai, onde se permanece certas horas de certos dias, e de onde se vem. Ao mesmo tempo, essa ocupação de espaço e sua conversão em lugar escolar levam consigo sua vivência como territórios por aqueles que com ele se relacionam. Desse modo é que surge a partir de uma noção objetiva a de espaço - lugar - uma noção subjetiva, uma vivência individual ou grupal, a de espaço - território (VIÑAO, 2005, p. 17).

Um território que começou a ser vislumbrado pelos estudantes de outras escolas que visitaram o Campus.

\subsection{A casa da educação: recebendo as} visitas

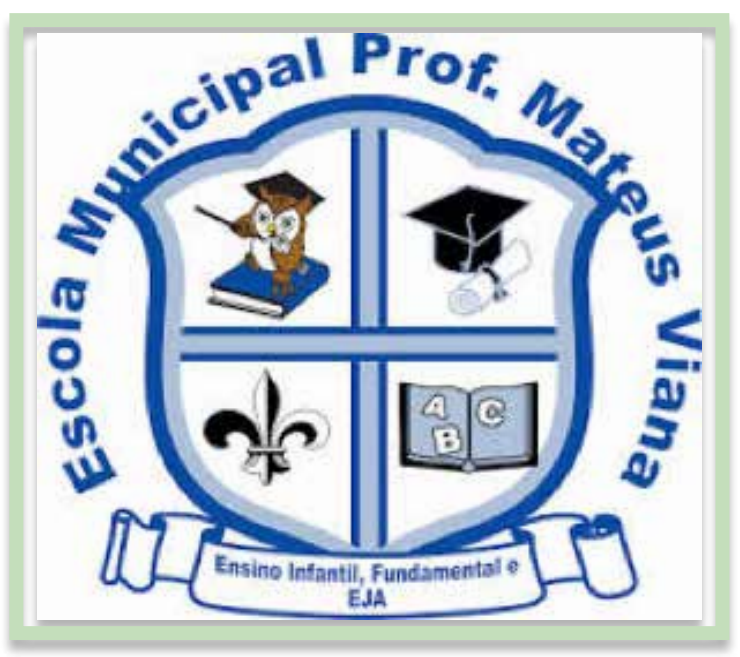

Figura 1: Brasão da Escola 


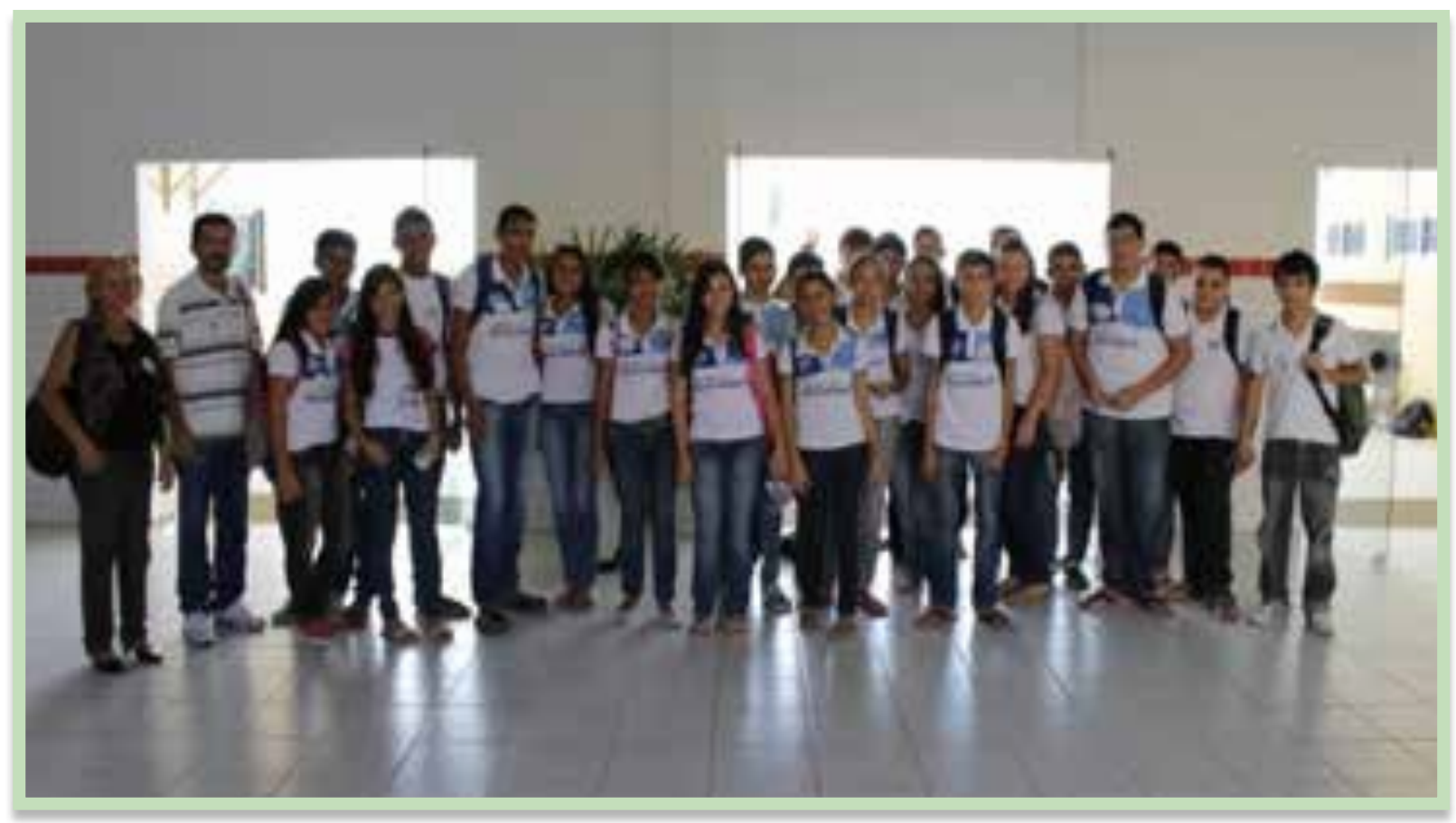

Figura 2: Estudantes da Esc. Mateus Viana

É impossível realizar bem o papel da educação sem compreender a realidade do entorno escolar, a história da sociedade com suas mudanças sistemáticas, as diferentes visões da educação, da psicologia, da sociologia, da filosofia, dentre outras. Mais do que nunca, vivemos em uma sociedade que avança em descobertas científicas, tecnológicas e neurocientíficas que favorecem à construção interativa do conhecimento.

Nesse aspecto, o Instituto Federal do Rio Grande do Norte possui um arcabouço científico e tecnológico que poderá ser socializado e divulgado para o público de onde, futuramente, poderá emergir um potencial estudante. Uma das formas de socializar esse conhecimento é abrir, literalmente, as portas da Instituição e fazer-se conhecer para os discentes de outras escolas públicas, como aconteceu com a Escola Municipal Professor Mateus Viana, a primeira a participar do Projeto de Extensão.

A visita dos estudantes da turma do 9 ㅇ ano ocorreu no dia 27 de agosto de 2013. Na ocasião, os estudantes participaram de palestras sobre os cursos de Informática, Eletrotécnica, Vestuário e Licenciatura em Física, que foram proferidas pelos
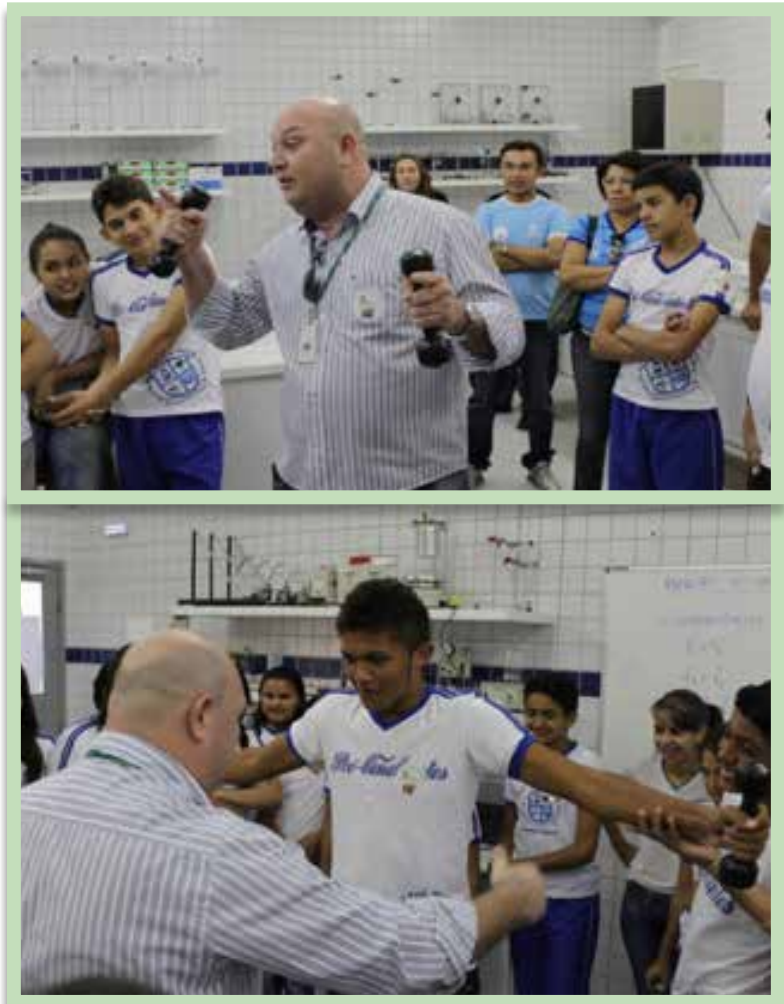

Figuras 3 e 4: Visita ao Laboratório de Física do IFRN Coordenadores dos respectivos cursos, visitando "in loco" os espaços físicos do Campus. 


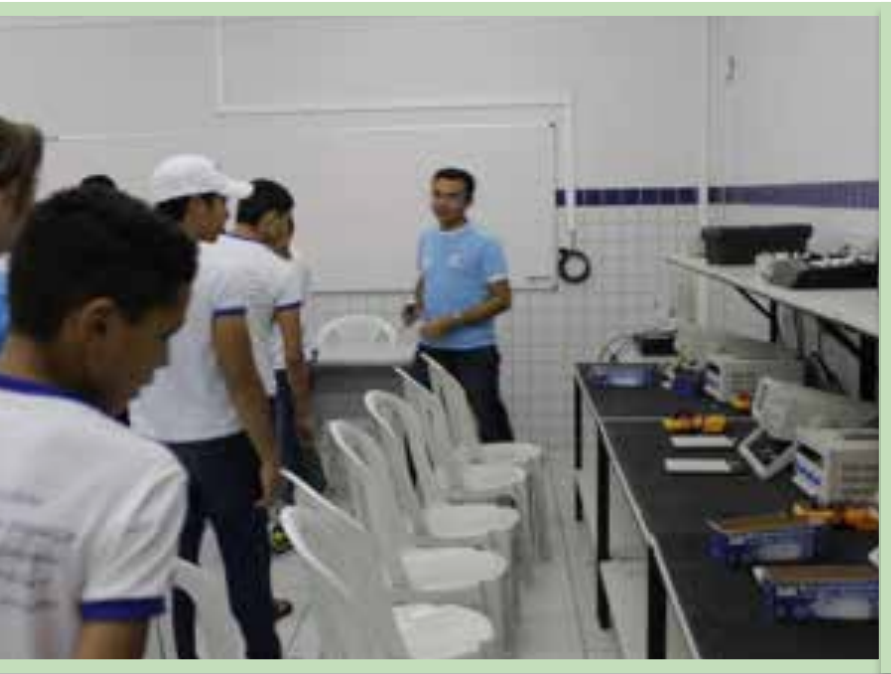

Figura 5: Visita ao Lab. de Eletrotécnica
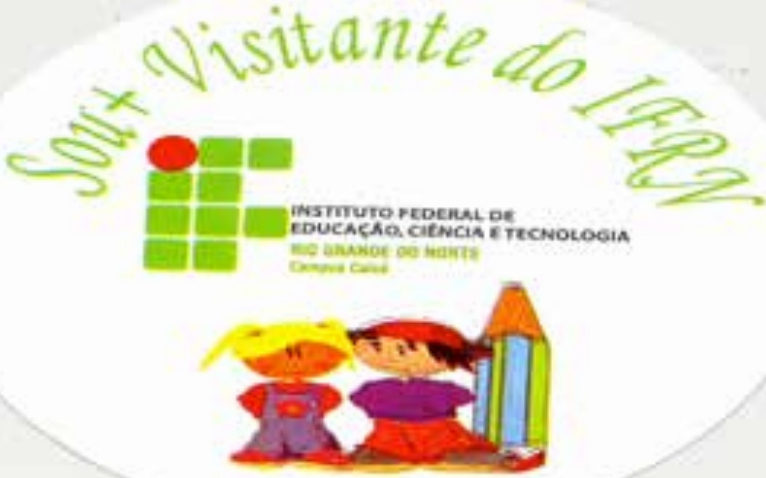

Figura 6: Adesivo que os estudantes recebem

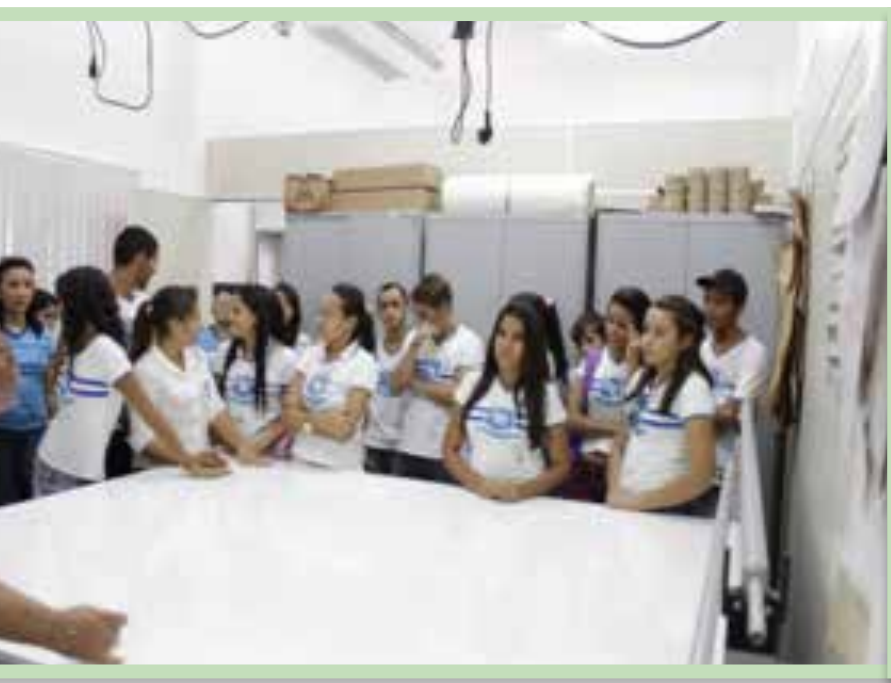

Figura 7: Visita ao Laboratório de Vestuário

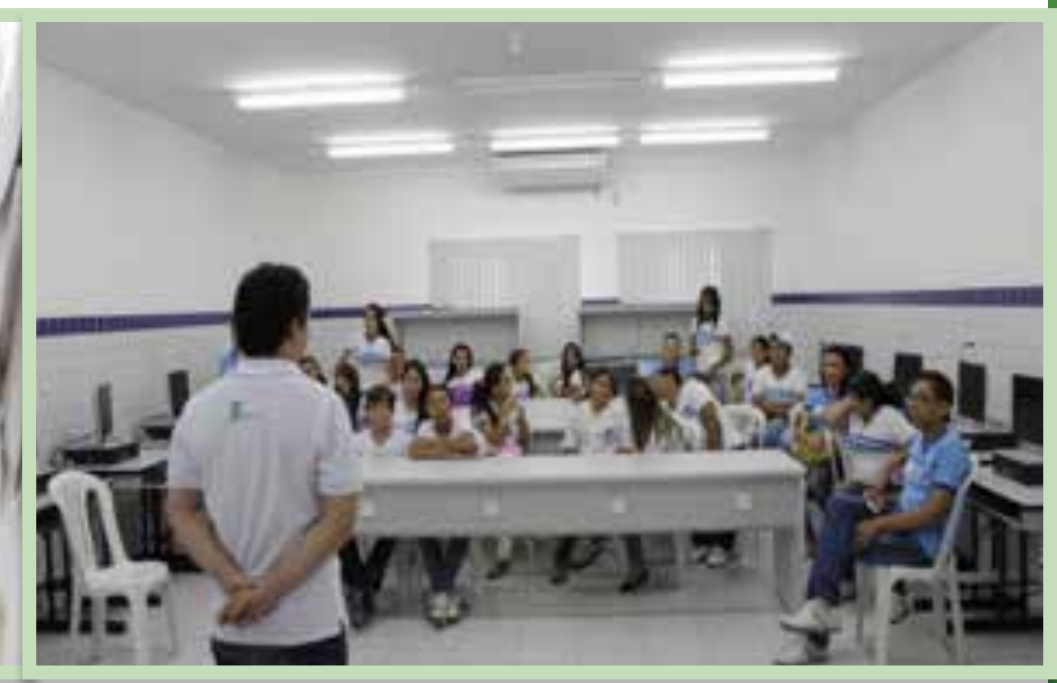

8: Visita ao Lab. de Informática

\section{CONCLUSÃO}

O IFRN atua em diversos níveis e modalidades de ensino, o que denota diferentes ofertas educacionais a distintos grupos destinatários atuais e/ou potenciais, como é o caso dos estudantes que visitam o Campus Caicó por meio do Projeto Diálogos sobre Educação Profissional. Esse Projeto foi pensado para desenvolver todas as ações educativas de modo globalizante, em particular, as ações de ensino, pesquisa e extensão.

A formação profissional que ora ofertamos nos Institutos Federais pretende integrar-se à formação dos estudantes nos aspectos culturais, econômicos e políticos, oportunizando a esses a consciência crítica de seu papel enquanto cidadão; o que denota a exigência de uma prática educativa que além de preparar para o mercado de trabalho, também dê a esses o direito a uma formação humana integral, capaz de contribuir para a consolidação de sua cidadania. Para a construção do processo de aprendizagem, tornase extremamente importante 0 aprendizado mútuo entre o educador e o estudante. Nesse aspecto, a escola tem a função de ser um espaço que favoreça a expressão dos estudantes, não os tornando meros expectadores em sala de aula.

O Projeto de Extensão Diálogos sobre Educação Profissional - Papo cabeça sobre os cursos ofertados pelo IFRN - Campus Caicó é uma ação do IFRN que contempla o ensino, a pesquisa e a extensão na medida em que envolve estudantes de outras escolas públicas estaduais e municipais, 
professores, bolsistas, voluntários e coordenador do Projeto, como também os Coordenadores de Cursos do Instituto Federal.

\section{REFERENCIAS}

INSTITUTO FEDERAL DE EDUCAÇÃO, CIÊNCIA E TECNOLOGIA DO RIO GRANDE DO NORTE. Histórico. Caicó, 2009.

INSTITUTO FEDERAL DE EDUCAÇÃO, CIÊNCIA E TECNOLOGIA DO RIO GRANDE DO NORTE. Regimento Interno. Caicó, 2009.

INSTITUTO FEDERAL DE EDUCAÇÃO, CIÊNCIA E TECNOLOGIA DO RIO GRANDE DO NORTE. Certidão [Estatutos]. Caicó, 2009.

INSTITUTO FEDERAL DE EDUCAÇÃO, CIÊNCIA E TECNOLOGIA DO RIO GRANDE DO NORTE. Manual do aluno. Caicó, 2009.

VIÑAO-FRAGO, A., ESCOLANO, A., (2005). Currículo, espaço e subjetividade: a arquitetura como programa. Rio de Janeiro: DP\&A. Tradução de Alfredo Veiga-Neto. 